\title{
ANALYSIS OF REINFORCED CONCRETE CONTAINMENT VESSELS CONSIDERING CONCRETE CRACKING
}

\author{
K. P. BUCHERT, T. A. BALLARD \\ Bechtel Power Corporation, \\ 15740 Shady Grove Road, P.O. Box 607, Gaithersburg, Maryland 20760, U.S.A.
}

\section{SUMMARY}

Cracking of concrete influences the stress analysis of concrete containment vessels. If cracking is ignored, the resulting shell analysis can be unconservative in some cases and extremely conservative in others. A cracked concrete shell is a structurally orthotropic one. That is, it does not have the same properties in membrane action and bending action.

The development of structurally orthotropic shell theory has progressed rapidly in all parts of the world and has been applied to stiffened shells (such as submarines, containment vessel liners, and underwater oil storage vessels), to stadium roofs (such as the Astrodome) and to the stability of reinforced concrete shells. It has also been accepted by the U.S. Structural Stability Research Council (formerly the Column Research Council).

The closed form solution for a cracked shell can be illustrated by resolving the differential equation of a cylindrical shell as given by Timoshenko for edge loadings. The equation is:

$$
D \frac{\mathrm{d}^{4} w}{\mathrm{~d} x^{4}}+\frac{E h}{a^{2}} w=Z,
$$

where $D$ is the shell bending rigidity and $E h$ is the shell membrane rigidity. Also, $w$ is the deflection, $a$ the radius and $Z$ the loading. In the case of a cracked concrete shell, $D$ is the modulus of elasticity times the moment of inertia per unit length of the cracked shell including reinforcing. Thus the shell action is dependent upon the amount of reinforcing steel as well as the thickness of the shell.

The above method has been used to solve for the forces and moments between a base slab and cylindrical shell on a reinforced concrete containment. Similarly the differential equations developed by Eringen, et al. for local effects due to openings have been resolved and have been used to analyze openings in containments for equipment hatches and personnel openings. The effects of internal pressure as well as other loads can be handled. Novozhilov's equations for local effects on shells have also been resolved using orthotropic shell theory. A more detailed derivation of the basic concepts and basic equation have been developed by Buchert.

Over the past few years, much interest has been generated within the universities by industry, to develop finite element programs capable of accurately predicting the behavior of reinforced concrete plates and shells, considering material nonlinearities. Although the programs thus far developed are for the most part, research tools, they are recently being considered for parametric studies to validate current design procedures. The finite element method presents a very straight-forward tool for considering material nonlinearities. structural irregularities and orthotropic behavior of concrete shells. Reinforcing can be accurately positioned and oriented within the thickness of the shell and partially cracked sections can be considered. - The method has been used successfully to predict the behavior of concrete shells by Scordelis.

Thus there are two general approaches that can be used to analyze reinforced concrete containment vessels considering concrete cracking. They are a) closed form solutions considering the structurally orthotropic shell properties and b) finite element programs that take into account the different membrane and bending properties of the element. 
I. INTRODUCTION

Cracking of concrete Influences the stress analysis of concrete contalnment vessels. If cracking is ignored, the resulting shell analysis can be unconservative in some cases and extremely conservative in others. A cracked concrete shell is a structurally orthotropic one. That 1s, it does not have the same properties in membrane action and bending action. The sketch below 1llustrates a typical situation In a concrete shell.

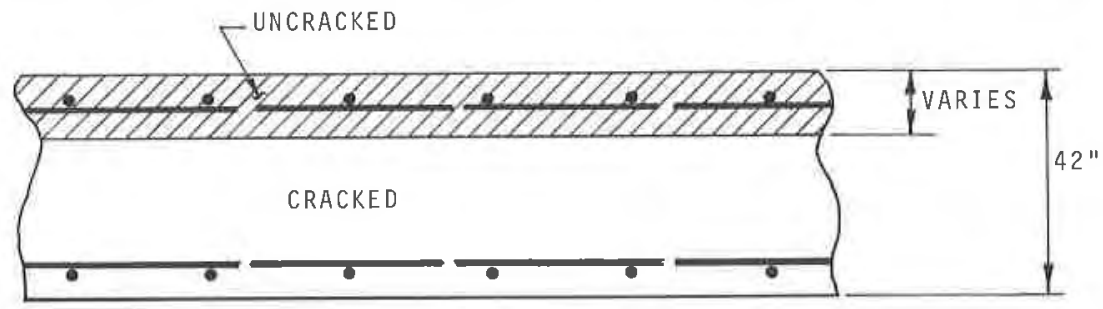

It is assumed that the she11 is reinforced with \#18 bars at 9 inches on centers each way on each face. Under relatively large membrane compression and bending the shell would be uncracked. The effective membrane thickness would be 42 inches plus the effective transformed steel area. Likewlse the effective bending thickness would be 42 Inches plus the effective transformed steel area. The detalled method of calculating the effective membrane and bending thicknesses will be 1llustrated later. In this case the relatively simple closed form shell equatons or the avallable finfte element methods could be used.

In the case of relatively large membrane tension, the concrete may be fully cracked and an entirely different situation exlsts. The effectlve membrane thickness is proportlonal to the transformed steel area and the effective bending thickness is a function of the moment of inertia of the transformed steel area. Thus there is no single thickness that can be used in the shell equations that will give correct results if both she-1 membrane and shell bending stresses extst. Fortunately, however, many of the shell equations have been resolved considering what is called split rigidity action and thus the designer can use the results in a similar way that has been done in 1sotropic shell design and analysis.

A similar situation exists in fintte element technology. Some designers use uncracked finfte element programs to calculate stresges in shells. In the case of thermal stresses, the uncracked finite element programs often give moments that are many times the actual moment when the section is cracked. If the shell section fllustrated above 1s uncracked 1t has a transformed bending rigidity of $2.76 \times 10^{10}$ lb-inches per inch. If $1 t$ is fully cracked the bending rigidity is $0.233 \times 10^{10} 1 \mathrm{~b}$-Inches per 1nch. Thus an uncracked section has about twelve times the bending rigldity of a fully cracked section. Similarly, the uncracked section has about nine times the axial rigidity of a fully cracked section. Some destgners reduce the moment due to thermal stresses in accordance with code rules. 
In order to develop more reallstic stresses, cracked section fintte element programs have been developed. In general these programs assume a number of elements through the thickness of the shell and vary the propertles of each element (for example, assume that E Is almost zero for concrete elements in tension). Usually some 1terative process is involved.

The purpose of thle paper is to 1llustrate some of the techntques that are avallable.

\section{CLOSED FORM SOLUTIONS}

In general, the closed form solutions of 1sotroplc shells can be resolved for structurally orthotropic shells by conoldering an effective membrane and an effective bending thickness (See reference [1]). T1moshenko [2] as well as others have shown the development of the differential equation for cylindrical shells loaded aymmetrically with respect to 1ts axis. Using the equations of equilibrium, it is shown that

$$
D \frac{d^{4} w}{d x^{4}}+\frac{E h}{a^{2}} w=z
$$

where

D is the flexural rigidity of the shell

Eh $1 \mathrm{~s}$ the axial or shear rigidity of the shell

a is the radius

w Is the deflection

$\mathrm{Z}$ is the lateral load.

This equation can be rewritten as follows:

$$
\frac{E t_{B}^{3}}{12\left(1-v^{2}\right)} \frac{d^{4} w}{d x^{4}}+\frac{E t_{m}}{a^{2}} w=z
$$

where

$t_{B}$ is the effective bending thickness

$t_{m}$ is the effective membrane thickness

For a relnforced concrete shell

$$
\begin{aligned}
& \frac{1}{12} t_{B}^{3}=\frac{I}{d} \\
& t_{m}=\frac{A}{d} \\
& t_{B}=\left(\frac{12 I}{d}\right)^{1 / 3}
\end{aligned}
$$

where

I is the effective transformed moment of Inertia over a length of shell d

A is the effective transformed area over a length of she11 d

Usually in solving the differential equation there is a quantity defined as:

$$
\beta^{4}=\frac{1}{\lambda^{4}}=\frac{E h}{4 a^{2} \mathrm{D}}=\frac{\mathrm{Et}_{\mathrm{m}} 12\left(1-v^{2}\right)}{4 \mathrm{a}^{2} \mathrm{Ft}_{\mathrm{B}}{ }^{3}}
$$


Using this substitution, one can find the deflections, moments and shears at any point In the shell as a function of $\beta$ or $\lambda$. Thus one only needs to compute $t_{m}$ and $t_{B}$ for an orthotropic shell and can then use all the solutions for this type of shell. This simple relationship has been used to find the cracked section moments and shears for a cylindrical relnforced concrete shell.

It is interesting to note some of the classical parameters for the shell detalls described in the introduction. These are given in the following:

\begin{tabular}{|c|c|c|c|}
\hline Parameter & $\begin{array}{c}\text { Uncracked } \\
\text { Section } \\
\end{array}$ & $\begin{array}{c}\text { Fully Cracked } \\
\text { Section }\end{array}$ & $\begin{array}{l}\text { Half Cracked } \\
\text { Section }\end{array}$ \\
\hline $\mathrm{t}_{\mathrm{m}}$ & 42 in.+steel & $0.66 \mathrm{ln}$. & $3.66 \mathrm{fn}$. \\
\hline $\mathrm{t}_{B}$ & 42 In.+stee1 & $9.57 \mathrm{1m}$ & $11.65 \mathrm{1n}$. \\
\hline$\lambda$ & 0.0072 & 0.0077 & 0.0102 \\
\hline D conc. + steel & $2.76 \times 10^{10}$ & $0.233 \times 10^{10}$ & $0.420 \times 10^{10}$ \\
\hline$\frac{3 \pi}{4 \lambda}$ & $27 \mathrm{ft}$. & $25.4 \mathrm{ft}$. & $19.2 \mathrm{ft}$. \\
\hline$\frac{\mathrm{D} \text { conc. }+ \text { stee } 1}{\mathrm{D} \text { actual }}$ & 1 & 12 & 6.6 \\
\hline $\mathrm{Et}_{\mathrm{m}}$ conc. + steel & 1 & 8.9 & 1.61 \\
\hline
\end{tabular}

These quantities 1llustrate that the solutions for a cracked shell can vary considerably from the solutions of an uncracked shell. They do fllustrate, however, that the character1stic lengths $(3 \pi / 4 \lambda)$ do not vary by a significant amount.

Thts same type of solution can be used to evaluate the effects of local loads on shells as well as the effects of openings. In addition, the critical buckling loads of cylinders, spherical shells and hypars have been calculated [3].

Bljlaard [4] has calculated the deflections, moments, shears and membrane loads due to local forces and moments on spheres. The equations have been resolved [3] and one can readily find the desired quantities by using the modifled Blflaard relationships

$$
\begin{aligned}
& w=c_{2} \frac{R P}{E\left(t_{B}^{3} t_{m}\right)^{1 / 2}} \\
& s=1.82 \frac{r}{R}\left(\frac{R}{t_{B}}\right)^{1 / 2}\left(\frac{t_{m}}{t_{B}}\right)^{1 / 4} \\
& u=1.82 \frac{r_{\circ}}{R}\left(\frac{R}{t_{B}}\right)^{1 / 2}\left(\frac{t_{m}}{t_{B}}\right)^{1 / 4}
\end{aligned}
$$




$$
\begin{aligned}
& N_{\phi}=C_{5} \frac{P}{t_{B}}\left(\frac{t_{m}}{t_{B}}\right)^{1 / 2} \\
& N_{\theta}=C_{6} \frac{P}{t_{B}}\left(\frac{t_{m}}{t_{B}}\right)^{1 / 2}
\end{aligned}
$$

Stmilarly the equations and results developed by Koh, Thiel and Eringen [5] for the stresses at openings in cylindrical shells have been resolved using split rigidity concepts. All of the results can be used $1 \mathrm{f}$

$$
\begin{aligned}
& B=\frac{1}{2}\left[\frac{3\left(1-v^{2}\right)}{R^{2} t_{B}^{2}}\right]^{1 / 4}\left(\frac{t_{m}}{t_{B}}\right)^{1 / 4} \\
& K B=\frac{1}{\left[12\left(1-v^{2}\right)\right]} 1 / 2 \quad t_{B}\left(\frac{t_{B}}{t_{m}}\right)
\end{aligned}
$$

The practical use of the above equations generally Involves estimating the effective amount of cracking and then using a sensitivity study to bound the final results.

\section{FINITE ELEMENT SOLUTION}

The orthotroplc behavior of refnforced concrete shells can be addressed using the finite element technique. The layered shell concept has been used by Hand, et.a1. [6] and others [7] to successfully predict the behavior of concrete plates and shells subjected to static loads. Reinforcing steel is modeled as a discrete layer with orthotropic materlal properties, coupled to the middle surface of the shell. Cracking is accomplished by modfying the material constitutive properties of the approprlate layer and recycling the solution until convergence is achieved. Using these techniques, fairly complicated $\mathrm{R} / \mathrm{C}$ shell structures have been analyzed.

Nuclear contalnment vessels and internal structures are generally very simple structures geometrically and the loads that cause cracking and major redistribution of forces and moments are mostly axlsymmetric in nature. Internal pressure loads, prestressing forces, and thermal gradients are of major concern for the design of these structures. A highly complex non-linear finite element solution ts not justified for the basic shell design.

The layered shell concept was extended to shells of revolution [8,9] and included In a computer program written for analyzing axisymetric structures for non-axisymetric loads [10]. Th1s code has been very useful for general andysis of contalnment structures and the first harmonic solution or axisymetric displacement solution is easily extended to the analysis for cracked concrete sections.

The orthotropic materlal behavior and 1ts non-1inear behavior can be easily modeled to predict the redistribution of the forces and moments and to directly calculate reinforcing and concrete section resultants. 
Relnforcing layers are offset from the shells middle surface through transformations and material constitutive relations expressed as:

$$
\begin{gathered}
\left\{\begin{array}{l}
N^{\prime}{ }_{\phi} \\
N^{\prime}{ }_{\theta} \\
N^{\prime}{ }_{\phi \theta}
\end{array}\right\}=A_{\phi}\left[\begin{array}{ccc}
E & 0 & 0 \\
0 & m E & 0 \\
0 & 0 & 0
\end{array}\right]\left\{\begin{array}{c}
E_{\phi}^{\prime} \\
E^{\prime}{ }_{\theta} \\
Y^{\prime}{ }_{\theta}
\end{array}\right\} \\
m=\frac{A_{\theta}}{A_{\phi}}
\end{gathered}
$$

where

$A_{\phi}$ is the reinforcing area in the meridional direction

$A_{\theta}$ is the relnforcing area in the hoop direction

The primed terms represent layer resultants.

The offset transformation alters the constitutive matrix, coupling the reinforcing layer to the shells middle surface. Thus:

$$
\left\{\begin{array}{c}
N^{\prime}{ }_{\phi} \\
N^{\prime}{ }_{\theta}^{\prime} \\
N^{\prime}{ }_{\phi \theta}
\end{array}\right\}=A_{\phi}\left[\begin{array}{ccc:ccc}
E & 0 & 0 & h E & 0 & 0 \\
0 & m E & 0 & 0 & m h E & 0 \\
0 & 0 & 0 & 0 & 0 & 0
\end{array}\right]\left\{\begin{array}{l}
E_{\phi} \\
E_{\theta} \\
\gamma_{\phi \theta} \\
k_{\phi} \\
k_{\theta}^{\phi} \\
k_{\phi \theta}
\end{array}\right\}
$$

In equation (15), $h$ is the distance from the middle surface of the shell to the centrold of the relnforcing steel. If the centrolds of the hoop and meridional reinforcing differ by a large amount, m can be modffied to account for this or a separate shell can be used for each direction, ellminating the proper terss in the constitutive matrix.

The concrete shell material model for an uncracked section is simply:

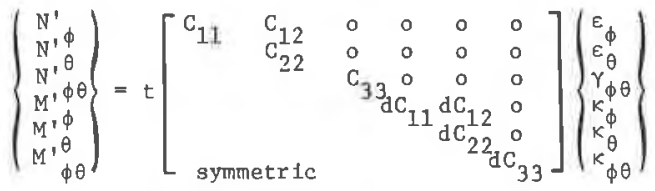

$$
\begin{aligned}
& d=\frac{t^{2}}{12} \\
& C_{11}=\frac{E}{1-v^{2}} \\
& \mathrm{C}_{22}=\mathrm{C}_{11} \\
& C_{12}=v C_{11} \\
& C_{33}=G
\end{aligned}
$$

This materfal model is used to determine the 1nitlal force and moment distribution for pressure and prestressing loads. Following the first cycle or prior to analyzing for thermal gradients, the section 1 s cracked and a new material model is formulated. Thus: 


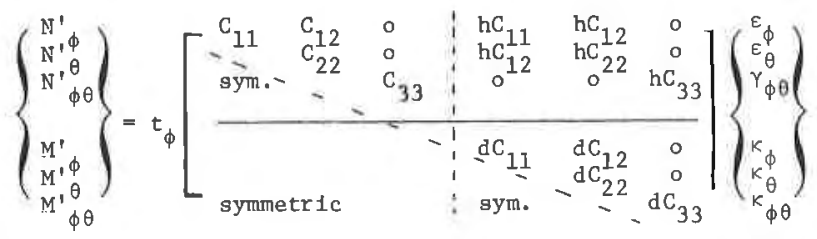

$$
\begin{aligned}
& d=\frac{t^{3}}{12}+h^{2} \\
& \mathrm{C}_{11}=\frac{\mathrm{E}}{1-v^{2}} \quad \mathrm{C}_{22}={ }_{\mathrm{mC}} \mathrm{C}_{11} \\
& \mathrm{C}_{12}=\mathrm{mvC}_{11} \quad \mathrm{C}_{33}=\mathrm{G} \\
& m=\frac{t_{\theta}}{t_{\phi}}
\end{aligned}
$$

The term $\mathrm{h}$ 1s determined by the amount of cracking that has taken place. Again, error is introduced if hoop and mertdional cracklng are not the same, but this is overcome In the same manner that unequal relnforcing centrolds are handied.

The approach presented here for predicting the distribution of forces and moments for a concrete shell of revolution is not as rigorous or exact as many that have been suggested, but is sufficlent for this type of design work.

\section{REFERENCES}

[1] Buchert, K. P., "Buck11ng of Relnforced Concrete Sphertcal Shells," 2nd Internat1onal Conference on Space Structures, Gulldford, England, September 1975.

[2] Timoshenko and Wolnowsky - Krleger, "Theory of Plates and Shells," McGraw-H1l1, 1959.

[3] Buchert, K, P., "Buckling of Shell and Shell-L1ke Structures," K. P. Buchert and Assoclates, 1973.

[4] B1jlaard, P. P., "Computation of the Stresses from Local Loads in Spherical Pressure Vessels or Pressure Vesse1 Heads," Welding Research Counc1l Bullet1n 34, 1957.

[5] Koh, S. L., Thiel, C. C. and Eringen, A. C., "Computations for Stresses and Stress Concentration In a Circular Cylinder Shell with a Circular Cutout," General Technology Corporation, Apr 111963.

[6] Hand, F. R., Pecknold, P. A., and Schnobrlch, W. C., "A Layered Finite Element Nonlinear Analysis of Relnforced Concrete Plates and Shells," University of Ilinois, Structural Englneering Serles Number 389, August 1972.

[7] Lin, C. S. and Scordelis, A. C., "Nonlinear Analysis of RC Shells of GeneraI Form," ASCE Journa1 of Structural Division, Vol. 101, No. ST3, March 1975, p. 523.

[8] Ambartsumyan, S. A., "Theory of Axisotropic Shells," National Aeronautics and Space Adminfstration, 1961 .

[9] McChesney, R. S., "Improved Finfte-Element Analysis of Nuclear Contalniment Shell Structures," Los Angeles Calffornia, March 1972.

[10] Ghosh, S., and Wilson, E., "Dynamic Stress Analysis of Axisymmetrfc Structures Under Arbitrary Loading; Report No. EERC 69-10, College of Englneering, Untversity of Callfornia, Berkeley, Callfornia, September 1969. 